Psychology of Language and Communication 2020, Vol. 24, No. 1

\title{
Sciendo
}

DOI: $10.2478 /$ plc-2020-0002

\author{
TIJANA HIRSCH, ORLY KAYAM \\ Wingate Academic College, Tel Aviv, Israel
}

\section{ACADEMIC MOTHERS' DEFINITIONS OF BILINGUALISM, BILINGUALITY, AND FAMILY LANGUAGE POLICIES}

\begin{abstract}
Bilingual partnerships (Piller \& Pavlenko, 2004) and transnational families (Hirsch \& Lee, 2018) are on the rise. With mothers spending more time with their children at home, even in dual career partnerships (Hochschild \& Machung, 1989), the labor of family language policy (FLP) implementation often falls on them. While increasingly more new hires in academia are women (Finkelstein, Seal, \& Schuster, 1998), only $31 \%$ of them are mothers (Perna, 2003). In this work, we examine the dominant discourses regarding bilingualism and FLP among academic mothers who find themselves at an intersection of multiple and often competing social positions. Data was collected from 46 academic mothers residing in linguistically-different host societies but all whom gather in an online community they have co-created. Data collection procedure included 22 open-ended questions exploring bilingualism and FLP orientations. Iterative and recursive content analysis was performed, yielding thematic patterns centering around language ideologies, practices, and bilinguality.
\end{abstract}

Keywords: bilingualism, academic mothers, family language policy, transnationalism

Bilingual relationships are on the rise internationally (Piller \& Pavlenko, 2004), as are bilingual and transnational families. Within bilingual and transnational families, one of the key issues that has been addressed on an ongoing basis is language: which language to learn, maintain, and use (Hirsch \& Lee, 2018). Through language, relationships are built and maintained, and in families, languages are learned, retained, or forgotten (Fishman, 1991; Spolsky, 2012). Family is the "critical domain" (Spolsky, 2012) for language vitality, and the study of family language policy (FLP) explores ideologies that guide

Address for correspondence: Tijana Hirsch, Wingate Academic College Wingate Post, Netanya 42902, Israel. E-mail: tijana-h@wincol.ac.il 
different language management approaches, resulting in different practices and outcomes (see King and Fogle, 2016; Kirsch, 2012; Spolsky, 2012; Wei, 2012).

But FLP ideologies, management, and practices are not created in the vacuum of a family domain, rather they are an outcome of complex and often competing ideologies of and between each individual family member and the temporal aspects associated with the family's settlement. The temporal aspect of the family's settlement refers to the initial plans associated with the move-as temporary or permanent-that influence orientations and attitudes toward many aspects of the settlement, including language ideologies, management, and practices (Hirsch \& Lee, 2018). The temporal aspect and the initial plans are relevant to our work as most of our participants have moved and/or live(d) outside of their birth countries.

Individual language ideologies that guide management approaches and practices are a product of different social memberships and experiences, language politics, language valorization (Hamers, Blanc, \& Blanc, 2000), social capital (Bourdieu, 1977) associated with different languages, and individual goals. Thus, gender, race, sexuality, social class, education level, and marital status all contribute to the individual and collective ideologies that, in turn, affect FLPs. Furthermore, individual experiences with language contact or bilinguality (Hamers \& Blanc, 1989) are important in guiding future FLPs. Hirsch (2017) found that although mothers consulted friends in similar bilingual situations, and literature or professionals to lesser degrees, they largely relied on past personal experiences in decision making regarding FLP management.

In the present work, we examine the discursive space of academic motherhood through post-structural orientations. We examine socially derived ideologies (Pavlenko, 2002) and experiences rooted in subject positions of gender, motherhood, education level, and social membership in academia that guide our participants' FLPs. We are not concerned with detailed implementations of FLPs; rather, we focus on academic mothers' decision to transmit a language or not, and the experiences that led to those decisions. We do so through analyses of their definitions of bilingualism, and the effects of language contact on the individual through bilinguality (Hamers \& Blanc, 1983). With language being the "...main site of world and identity constructions" (Pavlenko, 2001, p. 121), we examine how this particular, elite, and rather small community of practice (Lave \& Wenger, 1991; Wenger, 1998) defines bilingualism, as we explore their individual bilingualism through bilinguality - explained as "the psychological state of an individual who has access to more than one linguistic code as a means of social communication; the degree of access will vary along a number of dimensions which are psychological, cognitive, psycholinguistic, social psychological, social, sociological, sociolinguistic, sociocultural and linguistic" (Hamers, 1981, as cited in Hamers et al., 2000, p. 6)." In the sections below, we first discuss 
the gendered experience of languaging within the family, academic motherhood, bilingualism, and bilinguality, before turning to our findings.

\section{The Gendered Experience of Languaging Within the Family}

With exogamy on the rise (Wang, 2012), couples face complex decisions - from language use between the couple to country of settlement and, in some cases, the intended length of that settlement. The key factors influencing language choice or use between the exogamous couple are place of residence and proficiency (Piller, 2002), with women more likely to move into their husband's country (Kayam \& Hirsch, 2014; Piller, 1999; Piller \& Pavlenko, 2004). This often places women in situations of hindered access to linguistic, social, and economic capital, and the task of language learning, language transmission or loss. In transnational or immigrant families, where both parents speak the same language and come from the same linguistic background, it is the mother who is automatically tasked with language maintenance (Harvey, 1994; Hill, 1987; Zantella, 1987). In exogamous couples, the "invisible work" of language choice and socialization is, once again, the task of the mother (Okita, 2002). Even in dual-career partnerships, mothers spend more time at home with the children, and the labor of language socialization falls within the woman's "second shift at home" (Hochschild \& Machung, 1989, p. 25). In some cultures and societies, this remains to be true for husband's/father's heritage language that the wife/mother is less proficient in. Thus, although FLPs are continuously (re)negotiated between individual family members and are influenced by multiple other factors, it is most often the mother that initially implements the FLP and bears the brunt of the labor in language transmission and maintenance.

Women respond to their role as language socializers in complex ways. Some embrace the challenge of being the agent of heritage and language transmission and maintenance, while others are inspired by their very position to lead the family away from the traditional and towards the new, initiating the language shift (see Gal, 1978). In exogamous partnerships, some women maintain and pass on their language and/or their husband's language to the next generation, and some do not. These different responses to their positions are captured by bilinguality and are rooted in their multiple and sometimes competing roles and identities, with diverse factors affecting these decisions (Lanza and Wei, 2016; Piller, 2002; Walters, 1996). Bilingual women's experiences are different than those of bilingual men, and working mothers' experiences are different than those of working fathers' (Spitzmüller \& Mathews, 2016) because "women usually have a different life-cycle and life experience from men, though the ways in which these differ vary widely across cultures" (Burton, 1994, p. 4), and these differences are significant because of women's roles as mothers (Edwards, 1985). 


\section{Academic Mothers and Motherhood}

Even though increasingly more new hires in academia are women (Finkelstein et al., 1998), academic mothers are a minority - only $31 \%$ of female professors in the US have children (Perna, 2003). In fact, academic mothers are less common than medical-doctor or lawyer mothers (Uhlenberg $\&$ Cooney, 1989). The perception of academic careers as all-consuming, where "the ideal worker is married to his or her work" (Ward \& Wolf-Wendel, 2004, p. 5), as well as international mobility as a career requirement (Guignard, 2015) is problematic for those interested in having children, particularly for women - who are usually the primary caregivers even in dual career couples (Hochschild \& Machung, 1989). In addition to juggling professional, parenting, and household demands, these women are also faced with the key role in language maintenance, transmission, and learning efforts within the family in bicultural or bilingual situations and partnerships, as discussed above.

In this work, we transcend national borders and approach academic mothers in bilingual situations as a community of practice (Lave \& Wenger, 1991; Wenger, 1998) - a community that shares the experiences of simultaneous mothering, academic labor, and bilingualism, regardless of their geo-location, ethnicity, class, or sexuality. This international group of academic women is a community (of practice) voluntarily gathered within the online community by the same name - sharing and supporting each other within the boundaries of the online space they co-create, with their experiences and needs transcending international borders. The reason we find this population particularly interesting is that in our view, academic women and mothers live at the intersection of the traditional and the progressive, and the majority and the minority roles and experiences. We are able to learn about the dominant and domineering social discourses from women who are exposed to a variety of discourses through their intersectional social memberships.

\section{Bilingualism and Bilinguality}

Definitions of bilingualism are abundant, and fraught with contradictions, opinions, and biases: "As bilingualism defies delimitation, it is open to a variety of descriptions, interpretations, and definitions" (Hoffman, 2014, p. 14). They are rooted in perspectives and ideologies informed by the subject positions in social memberships and resulting experiences. If we consider the diversity of individual experiences with two or more languages, different abilities, varied dominance, and development on the continuum from passive and receptive to active and productive (Valdés, González, García, \& Márquez, 2003), to emerging bilinguals in the early stages of learning (García, 2009), it is impossible to define it as anything other than "relative" (Mackey, 1970, p. 555). 
This is troubling to scholars and non-scholars alike. People like categorizing, and the inherent diversity of bilingual expressions and experiences is a disconcerting one. In academia, to study something, we need to define it, delimit it, and operationalize it. Hence, in a relatively early attempt to define bilingualism, Bloomfield (1933), as cited in Hoffman (2014), falls into the trap of contradiction when it comes to bilingual definitions. To Bloomfield's statement: "In the cases where this perfect foreign-language learning is not accompanied by loss of the native language, it results in 'bilingualism,' native-like control of two languages. After early childhood, few people have enough muscular and nervous freedom or enough opportunity and leisure to reach perfection in a foreign language; yet bilingualism of this kind is commoner than one might suppose, both in cases like those of our immigrants and as a result of travel, foreign study, or similar association. Of course, one cannot define a degree of perfection at which a good foreign speaker becomes a bilingual: the distinction is relative" (p. 56), Hoffman responds: "No doubt Bloomfield had a clear notion of bilingualism, but his definition and subsequent qualifying remarks are not without some degree of contradiction: If one cannot define 'a degree of perfection' in bilingualism, how can we talk of 'perfect foreign-language learning'?" (p. 15).

We found Weinreich's (1968) attempt at objectivity and brevity in defining bilingualism to be commendable. He proposes that "the practice of alternately using two languages will be called bilingualism, and the person involved, bilingual" (p. 1). The "practice" is not qualified by adjectives such as perfectly, or fluently; the "alternately" is ambiguous, and no specific time frames such as since birth, daily, etc., are imposed. Weinreich makes a distinction between the "practice" and the "person."

Hamers and Blanc (1983), on the other hand, make a distinction between the societal and the individual experiences stemming from language contact. They define bilingualism as the effect of language contact on society as a whole, and bilinguality as the non-linguistic effects of bilingualism on the bilingual individual. Bilingualism, according to Hamers et al. (2000), "refers to the state of a linguistic community in which two languages are in contact with the result that two codes can be used in the same interaction and that a number of individuals are bilingual (societal bilingualism); but it also includes the concept of bilinguality (or individual bilingualism)" (p. 6).

Though this distinction is an important one, we must acknowledge that while individual bilingualism is common, societal bilingualism, as described above and as we understand it, is not necessarily common. Within the United States, for example, individual bilingualism is common while societal bilingualism is minimal. In other words, in different nation state contexts, different codes cannot be used equally throughout society (Crawford, 1992). In the case of Israel, although the official language policy of the country de jure was, up until recently, bilingual with Arabic and Hebrew as the two 
official languages, de facto Arabic could not be used equally throughout all areas of society (Spolsky, 2001). Individually, Arabs and some Jews may have been bilingual in Hebrew and Arabic but Arabic could not be used to achieve all of the desired communicative goals equally in all areas of the society. While officially quadrilingual, Switzerland is argued to be bilingual at best (Kużelewska, 2016), with different code combinations present at the individual level but unsupported in different areas of society. In the context of United States, in the same interaction, two codes cannot be used equally throughout society (Crawford, 1992). In some communities within the United States, particularly those that are bilingual in English and Spanish, this may be the case to a certain degree, but equality in use and usefulness is not assumed.

As such, we most closely subscribe to Grosjean's (1982) \& Piller and Pavlenko's (2004) definitions of bilingualism and bilingual practices of individual bilingualism or bilinguality as inclusive - of two or more languages, "irrespective of proficiency and age of acquisition" (Piller \& Pavlenko, 2004, p. 489). However, we removed the condition of their use to be restricted to "on a regular basis," due to the heterogeneity of experiences, situations, and opportunities that are available to different individuals and groups to use the languages in their linguistic repertoires. In our conceptions of bilinguals $^{1}$, we also include individuals who choose not to partake in bilingual practices but who have more than a single code available to them. The non-linguistic reasons, experiences, and emotions behind those choices or decisions are invaluable in understanding the individual bilingual experiences that influence the future of bilingualism within families and societies. In this study, we explore both academic mothers' definitions of bilingualism and their discourses about bilinguality in their FLPs.

\section{Method}

\section{Participants}

Forty-six academic mothers took part in a survey consisting of 22 open-ended questions focusing on bilingualism and academic motherhood (see Appendix). The survey was designed as part of a larger study named 'Academic Motherhood and Multilingualism' and was disseminated via Google Forms. Google Forms allows for easy dissemination of questionnaires and surveys and anonymous data collection online.

Our survey was designed and disseminated and our study was conducted in accordance with the Association of Internet Researchers' (AoIR) ethical conduct of performing research in online settings. In accordance with the American Association for Public Opinion Research (AAPOR), our survey did

\footnotetext{
${ }^{1}$ Our view of bilingualism is in line with translanguaging (Williams, 1994) definitions that focus on meaningmaking (García, 2009) rather than specific skills, frequency, or spaces where the language(s) are used. Furthermore, we use the term bilingual to refer to both bilingual and multilingual individuals and situations. We do not discuss translanguaging and/or the bilingual/multilingual distinction as it falls outside the scope of this work.
} 
not include collection of consent forms, as they would link the individual to the answers provided, thus compromising anonymity. Our procedures allowed for ethical dissemination of the survey and collection of responses that could not be linked to any single individual, unless the individual chose to provide self-identifying information in the space provided at the end of the survey (see Appendix).

All of the participants' responses were recorded by the Google Forms tool and later downloaded for analysis. The mothers were reached primarily through the closed online community of practice (Lave \& Wenger, 1991; Wenger 1998) on Facebook, and were encouraged to share the survey with colleagues and other bilingual academic mothers. This community of practice is transnational, multicultural, and multilingual with all of the communications conducted in English. It is co-created by 14,500 academic mothers from around the world. One of the authors of this work is an active member of the community since several years.

As such, this study is an (online) ethnography (Markham, 1998; Hine, 2008) of an online community that includes authentic participation by one of the authors, observation, and the survey responses as part of the analytic process. Engagement and explorations of different aspects of online individual and communal experiences, such as member identity (Baym, 1998; Turkle, 1995) and community as social reality (Baym, 2000; van Dijk, 1998), among other topics, have been carried out for well over 25 years. Ethnographers follow people where they are. With increasing numbers of individuals engaging in online spaces and co-creating communities in online settings, many researchers have recognized the importance and value in following people into those online communities in order to learn about and from them. Ethnographic research carried out online has been referred to in different ways.

Kozinets (1998), for example, coined the term netnography to denote ethnographic research on the net, with some researchers following suit (de Valck, 2005) while others refer to their ethnographic work in online spaces as cyberethnography (Gajjala, 2004), virtual ethnography (Buchanan, 2000, Hine, 2008), or simply as ethnography (Baym, 1993; Cherny, 1999; Correll, 1995; Lysloff, 2003; Markham, 1998). Perhaps, as suggested by Baym; Cherny; Correll; Lysloff; and Markham, the distinction is not necessary, as the experiences that give rise to gatherings in online spaces, and the co-creation of those spaces are very real for those involved and no demarcation is necessary. People meet in online spaces to learn from each other, to support each other, and to socialize. The communities they form are as diverse as our world. For instance, heterosexual mothers meet online to seek and provide advice (Madge \& O'Connor, 2006; Hirsch, 2017), lesbians meet in an Electronic Bar: The Lesbian Café (Correll, 1995), senior Japanese internet users meet in online spaces to socialize (Kanayama, 2003), people meet in work-related communities (Whitty, 2003) or food-related communities 
(de Valck, 2005), to name just a few. Fernback (2007) explains: "The distinction between the 'real' and the 'virtual' has become much less useful as the Internet is firmly ingrained in daily cultural existence" (p. 53).

As such, the community of interest to our present work is the space within which mothers, active in academia, gather to discuss their work/home experiences of academic motherhood, regardless of their country of residence. The majority $(89 \%)$ of the academic mothers who took part in this survey had, at some point, lived outside of their birth-country, with roughly half of them residing outside of their birth-country at the time of their participation in the study.

While many countries and languages are represented in this sample, $80 \%$ of the mothers resided in English-dominant settings (in the US and Canada) at the time of data collection. Other societally-dominant languages included bilingual English, French, Spanish, and Hebrew. The 25 languages represented in this survey were English, French, Spanish, Catalan, Danish, Russian, Armenian, Azerbaijani, Hebrew, Norwegian, German, Italian, Chinese, Portuguese, Bengali, Croatian, Urdu, Swedish, Estonian, Bulgarian, Arabic, Greek, Dutch, Japanese, and Mandarin - listed here in no particular order.

When asked about the source of additional language(s) in their lives, 22 women indicated translocation, 18 indicated partnership/marriage, 10 indicated heritage, and 17 indicated choice - which included maintenance of previously-learned foreign languages. These selections were not mutually exclusive; more than one selection was possible and encouraged.

When asked to self-identify as monolingual, bilingual, or multilingual, $56 \%$ selected bilingual, $31 \%$ multilingual, and $13 \%$ monolingual, even though they had additional languages in their linguistic repertoires. In identifying their partners along the same lines, $52 \%$ of our participants reported their partners as bilingual, $21 \%$ as multilingual, and $27 \%$ as monolingual, again with additional languages present in their linguistic repertoires.

Our definition of academic mothers included mothers at any level of academia - including doctoral students to full, tenured professors, researchers, and any mothers who self-identified as an academic, based on their level of education and current or past professional activities that necessarily included an academic institutional setting. Most mothers in this survey were, at the time of the survey, employed by academic institutions (41); of those, 27 academic mothers were employed as professors (assistant, associate, and full); 6 as an instructor, lecturer, or adjunct; 2 as researchers, 4 as post-docs, and 5 who were doctoral students, some of whom were also employed by an academic institution as staff members.

\section{Procedure}

We downloaded each participant's survey responses and all of the responses to each question separately. We iteratively and recursively revisited 
each answer as a part/whole relationship, zooming into each answer and zooming out to all of the information provided by the participant, in order to contextualize the answers within the individual's lived experiences. We analyzed and interpreted the answers inductively, allowing "the patterns, themes, and categories of analysis to come from the data" (Patton, 1980) through content analysis. As Ward and Wolf-Wendel (2004) pointed out, this method of analysis is particularly suitable in studies with limited prior research on the topic of interest and qualitative approaches are particularly appropriate "because the topic is rooted in women's experiences, which is best understood from the women themselves" (p. 240).

Through the acts of iterative and recursive content analysis, in addition to learning about their ideologies through definitions of bilingualism, two additional and recurring themes emerged: bilinguality and language practices. We thus organize our findings along these themes and include extracts of the participants' shared experiences for illustrative purposes while keeping in mind that the representations of them in our analysis are our own interpretations of them. Interpretations are rooted in triangulation of researchers' participation, observation, and the responses provided.

\section{Results}

\section{Defining Bilingualism}

Forty-four (96\%) academic mothers in our study focused on oracy, defining bilingualism as the ability to comprehend and communicate in two or more languages. A few included literacy skills in their definitions as well, with both reading and writing included in the definitions of only four $(9 \%)$ participants. While some definitions were inclusive and focused on function, such as "being able to survive daily life in the language," or "ability to carry out real interactions in a significant way in more than one language, ... perfect fluency isn't required, but the ability to navigate life is," most definitions were rather inflexible and stringent. This stringency focused on delimiting bilingualism along the lines of fluency, frequency of use, and age of acquisition.

Adjectives used to describe the level of fluency required for inclusion in their bilingual conceptions commonly included "dynamic" and "great," with switching between languages needing to be "effortless." For some, the level of fluency had to be so great that the person in question would be able "to move there and become a "native' speaker if they want(ed)," and some required full proficiency across domains "for both languages to be used across a variety of different contexts such as work, pleasure, and family."

Some participants focused on the actual amount of use in terms of waking-hours, requiring the bilingual to be "exposed to both languages at least $30 \%$ of their waking hours." Many required the language to be learned during childhood: "Technically I would consider any language learned during 
childhood to the point at which a person can effortlessly switch back and forth to be part of their bilingual/multilingual repertoire. For that reason I would not count myself bilingual, but I did answer affirmative to that question above given that I notice myself mixing languages in one sentence when talking to my kids."

Interestingly, this tough, stringent attitude did not apply to everyone and to all ages. Many of the mothers had different standards for children to be considered bilingual, all of them much more lenient: "For children - when they understand what the other party is saying and are able to answer even if not with proper grammar or wording... when the communication is there."

\section{Individual Bilingualism: Bilinguality}

Bilinguality, as mentioned earlier, refers to the effect of language contact on the individual, the experiences resulting from language contact, and the emotions experienced at different times. We were interested in exploring bilinguality of these women in order to better understand their lived experiences that may contribute to their FLPs. When asked to discuss their early experiences with and memories of language learning, two themes emerged. One centered around their emotions, desires, and needs when learning the new language and connecting with others through the target language, and the other centered around their experiences and emotions regarding the attitudes of the other(s) toward their language use and efforts.

Most of the women expressed positive attitudes toward their efforts - they wanted to learn, were excited to learn, and wanted to connect: "I loved and learned the new language. It was a way to connect with locals even though they could understand a third common language. I loved it very much." When discussing their experiences in terms of attitudes of the other(s), however, many reported having negative experiences. Some were bothered by the lack of opportunities to use the target language: "I hate it, people always wanted to speak to me in my native language to practice with me." Others were treated with lack of respect and endured attitudes and comments that were hurtful and that they, in some cases, internalized: "It was so hard - they thought I was stupid because I didn't know the language. They heard me speak quickly to my parents on the phone, and commented, 'Wow, you can speak quickly;"” "It was hard. I had to go to college in a different language. I worked super hard. It made me think I was not smart enough until I realized it would have been easier in my own language;" and "It was hard, people were mean and condescending about my accent and I hated sounding like an idiot, but I liked learning to navigate a new language and culture." The link between the two, their desire and drive to succeed and the negative experiences with others, in some cases, made lasting, negative impressions on some women: "You will always feel alien and irrelevant." In addition to negative or challenging emotions and experiences, such as feeling alien, irrelevant, or 
stupid, as mentioned above, several women also reported physical symptoms associated with the process: "It gave me a daily headache for two weeks..." or "I remember being exhausted - not just mentally, but physically, with my mouth and cheeks tired from being used in different ways for so many hours a day..."

Although challenging, difficult, exhausting, and uncomfortable, those who evaluated their experiences as positive overall seemed to have had luck in coming across supportive and positive individuals within the target language and/or host culture. Some directly attribute their successes and positive experiences, at least in part, to their host family (in the cases of study-abroad or home-stay programs) and their warm and helpful welcome: "I found learning Japanese informally in an immersion setting to be even more fun than school language courses; this was partly because I adored my host family and just wanted to be able to talk with them (we are still in touch 30 years later)..." And another: "I lived in Mexico for five months ... I was so grateful for the host family I lived with for initially accompanying me on daily errands so I could learn contextual details..."

\section{FLP Ideologies: Academia in Bilingual Mothering}

Although some mothers self-identified as monolingual, they had more than one language in their linguistic repertoires and routinely engaged in bilingual mothering. When asked to reflect on how the academic part of their experience contributes to their definitions of bilingualism, decisions and approaches concerning the languages, and management of those languages in their lives, the vast majority (93\%) of the participants reported a direct link. While some cited their professions, positions, and research interests as directly related to their views, such as those in linguistics, developmental psychology, or language instruction, most reported relying on academic sources. In addition to answering the question in the affirmative with "a lot" or "crucially," most of them cited "research," "studies," and "literature" as guiding their decisions. Phrases such as "...backed through research," "discussed in research," and "informed by the literature" were commonly (93\%) used to describe how the academic part of themselves contributed to their views and bilingual practices.

Furthermore, some of the participants emphasized the importance of culture and its inseparability from language. In fact, for some, culture was as much part of the equation as the language: "Facility of comprehension, writing, and expression and cultural understanding of more than one language/cultural group;" "Fluent in two languages with knowledge of the corresponding cultures;" "Full immersion, proficiency, and awareness of a different language and culture." These personal definitions of bilingualism furthermore embody the academic conversations of linguistic anthropological leanings à la Agar's (1994) languaculture. 


\section{FLP Practices: To Use or Not to Use?}

When asked whether there were language(s) in their repertoire that they chose not to maintain, 15 women responded in the affirmative. Most commonly, these decisions were either rooted in the lack of a community and opportunities to use the language within the new host settings: "I don't have many Estonian speaking people in my everyday life here in the U.S. Also, with the kids I wanted to focus on just one language." Or, this decision was liberating in a sense - a choice not to pass the languages on, because they no longer served a purpose in their lives and they felt no connection to it. One participant, for example, explained: "We belonged to the ethnic and linguistic minorities of our home countries, so these languages do not form a big part of our identities."

Interestingly, however, in same-sex partnerships, the academic mothers that participated in our research also answered for their wives/partners. For these women, their partners' linguistic background seemed to be as important as their own - maybe even more: "My family is Anglo back as long as I can see. My kids have Jewish heritage; my wife never learned either Hebrew or Yiddish from her family (her dad was very assimilated), but as we have tried to integrate some Jewish traditions into our family, and we have tried to introduce those linguistic elements where we can. Since I speak Arabic, I'm the one stuck trying to speak Hebrew since they share a sound system!"

\section{Discussion}

With studies relying on self-report measures, qualitative approaches, and inductive analysis when studying any dimension of the bilingual experience, language contact situations, bilinguality, family language policy, etc., it is important to first learn how the participants define what we are interested in studying. With little consensus on definitions within the academic communities, diversity of definitions among participants is to be expected. Asking participants how they define a construct of interest enables us to fully understand what we are studying. In addition, it provides us with information imbued in discourses stemming from different and subjective social memberships. Thus, through the question, "How do you define this concept?" we will know not only what it is that we are studying, but also the answer to "What have you learned through your experiences?"

In previous research, a discrepancy between what the author refers to as the 'lay view' and the 'academic view' of bilingualism was found, with the former view relying heavily on the notion of "ideal native speaker as the benchmark" (Zubrzycki, 2019, p. 447) and the latter becoming increasingly more flexible and inclusive over time. Academic mothers straddle the line 
between the two, so to speak, as they are both, lay people through motherhood as well as academics who are not necessarily involved in research and formation of views on the topic of bilingualism.

In the present work, however, we approached our community of interest-the community of academic mothers-as having above average know-how and access to information on any topic, including the topic of bilingualism because of their academic and professional ties and experiences. We expected the participants' positions and experiences relating to their memberships in academia to play some role in their definition of bilingualism and their approaches in FLP.

Interestingly, while most academic mothers indeed reported that their membership in academia plays a major role in how they approach bilingualism and FLPs, with literature repeatedly cited as key in their decision making, through our analysis we uncovered that in actuality, their approaches and orientations are deeply rooted in their personal past experiences and bilinguality. This is in line with previous research which shows that mothers-regardless of whether they consult the literature, professionals, or their friends for advice-rely on past personal experiences in making FLP decisions in regard to their children (Hirsch, 2017). Even though some mothers in our study provided definitions of bilingualism that were written in academic language or that echoed definitions of linguistic anthropological leanings, à la Agar (1994) and his concept of languaculture, when discussing their FLPs, even these participants relied on their past, personal experiences in guiding their reported ideologies, management, and practices.

Academic mothers are insistently demanding of themselves. They have different definitions and standards for inclusion in bilingualism for their children, and for themselves. Interestingly, those that made distinctions did not generalize to all adults, they specifically applied different standards to themselves - tougher, stricter, less inclusive standards. This, too, may be the result of their past experiences, perhaps the attitude they adopted in reaching for and achieving goals of academia and mothering concurrently: Not compromising where and when they were expected to compromise.

In some cases, they had to balance the biological and the tenure clocks, which are, unfortunately, very often concurrently unyielding. Although flexible in their definitions for others, they applied the monolingual norms on themselves, requiring of themselves to be the two monolinguals in one in order to count as bilingual, an idea that has been famously refuted by Grosjean (2006).

Some also seem to have internalized the socially constructed native speakerism (Holliday, 2006, 2013, 2015; Inbar-Lourie, 2005) or the idea that native is better than non-native (as in studies of English language teachers), all stemming from different sources such as the one-nation-one-language ideologies and the monolingual mindset (Piller and Gerber, 2018). We found this to be particularly surprising and contradictory given their educationally 
privileged positions, access to resources, and their reported consultations with literature on the subject of bilingualism and language management.

In this study, academic mothers are approached as a community of practice, transcending national borders and socio-political contexts - because they do so themselves. They gather in the online community and share what seems to be universal cares and concerns of academic mothering. Although we transcended (inter)national borders by meeting women online, our findings point to the importance of experiences within the (host) settings as key in their evaluation of their experiences with learning the new language. Those who felt welcomed and supported were much more positive about their overall experiences in learning additional languages. Those experiences, in turn, influenced their ideologies regarding language learning, maintenance, or loss, thus guiding their FLPs.

The approach of the current study did not factor in the individual realities associated with the socio-politics of the participants' countries of residence, or their subjective positions and experiences within that setting in terms of race, sexuality, and socioeconomics - to name a few. This is a limitation in our study. We recognize that experiences rooted in these subjects' positions and set in different host settings produce different opportunities, access, and overall experiences that guide future actions. Designing future studies to explore the interplay between different subject positions would provide more nuanced accounts of the bilingual experiences.

A link between sexuality and positions towards the partners' language maintenance efforts is suggested in the discourses of the academic mothers who are in a same-sex partnership. Academic mothers who communicated importance and concern over their partner's heritage language(s) in the discourses regarding their FLPs also mentioned being part of the same-sex partnerships. Following up on this link would be beneficial. Learning more about sexual orientations and orientations towards heritage maintenance (language and other) is an area worthy of further exploration.

Though not generalizable, our findings point to the importance of past, personal experiences and the role of the environment in those experiences in guiding future actions, regardless of the educational level. Creating welcoming and supportive spaces is key in promoting heritage (language) maintenance, mothering in academia, and positive outcomes in the future. Women seem to be turning to each other in online communal and safe spaces in search of support. The possibility to do so and the availability of such spaces may prove to be beneficial in all areas of life - including language maintenance efforts and mothering in academia. Online communities began as general spaces and have since become more and more specific and specialized: From country-specific to city-specific to neighborhood-specific; from parents of children of all ages to parents of babies, children, or tweens (Hirsch, 2017); from academic mothers to international academic mothers 
to academic mothers who write fiction. This trend shows that we seek spaces and groups where we fit in, both online and off. Studying the effects of the presence of these spaces on decisions, attitudes, and ideologies, as well as outcomes in all areas of social living are other areas of inquiry that should gain momentum. While the power of experience and environment is underscored, today more than ever we have the opportunity to create and find spaces of support that transcend the physical locations to which we are bound.

\section{References}

Agar, M. (1994). Language shock: Understanding the culture of conversation. New York, NY: William Morrow and Co.

Baym, N. K. (1998). The emergence of on-line community. Cybersociety 2.0: Revisiting Computer-Mediated Communication and Community, 35-68.

Baym, N. K. (2000). Tune in, log on: Soaps, fandom, and online community (Vol. 3). SAGE.

Burton, P. (1994). Women and second language use: An introduction. In P. Burton, K. K. Bloomfield, L. (1933). Language history: From language (1933 Ed.). New York, NY: Holt, Rinehart and Winston.

Dyson, and S. Ardener (eds.), Bilingual Women: Anthropological Approaches to Second-language Use (pp. 1-29). Oxford and Providence, RI: Berg.

Bourdieu, P. (1977). The economics of linguistic exchanges. Information (International Social Science Council), 16(6), 645-668.

Buchanan, E. A. (2000). Ethics, qualitative research, and ethnography in virtual space. Journal of Information Ethics, 9(2), 82.

Cherny, L. (1999). Conversation and community: Chat in a virtual world. Chicago. University of Chicago Press, 185-222.

Correll, S. (1995). The ethnography of an electronic bar: The lesbian café. Journal of Contemporary Ethnography, 24(3), 270-98.

Crawford, J. (1992). Hold your tongue, bilingualism and the politics of "English Only." Reading, Mass: Addison-Wesley.

de Valck, K. K. (2005). Virtual communities of consumption: Networks of consumer knowledge and companionship (No. 50).

Edwards, J. (1985). Language, society and identity. Oxford: Basil Blackwell (in association with Andre Deutsch).

Fernback, J. (2007). Beyond the diluted community concept: A symbolic interactionist perspective on online social relations. New Media \& Society, 9(1), 49-69.

Finkelstein, M. J., Seal, R. K., \& Schuster, J. H. (1998). The new academic generation: A profession in transformation. Baltimore, MD: Johns Hopkins University Press. 
Fishman, J. A. (1991). Reversing language shift: Theoretical and empirical foundations of assistance to threatened languages (Vol. 76). Multilingual Matters.

Gajjala, R. (2004). Cyber selves: Feminist ethnographies of South Asian women. Rowman Altamira.

Gal, S. (1978). Peasant men can't get wives: Language change and sex roles in a bilingual community. Language in Society, 7(1), 1-16.

García, O. (2009). Bilingual education in the 21st century: A global perspective. Chichester, UK: Wiley-Blackwell.

Grosjean, F. (1982). Life with two languages: An introduction to bilingualism. Cambridge, MA: Harvard University Press.

Grosjean, F. (2006). The bilingual is not two monolinguals in one person. World Englishes: Critical Concepts in Linguistics, 4, 202-213.

Guignard, F. P. (2015). Moving my brain to Canada: Motherhood and international mobility as an academic career requirement. Journal of the Motherhood Initiative for Research and Community Involvement, 6(2).

Hamers, J. F. (1981). Psychological approaches to the development of bilinguality. Elements of Bilingual Theory. Bruselas: Vrije Universiteit te Brussels.

Hamers, J. F., \& Blanc, H. A. (1989). Bilinguality and bilingualism. Cambridge. Harvey, P. (1994). The presence and absence of speech in the communication of gender. Bilingual Women: Anthropological Approaches to Second Language Use, 44-64.

Hill, J. (1987). Women's speech in modern Mexicano. In S. Phillips, S. Steele, \& C. Tanz (Eds.), Language, Gender and Sex in Comparative Perspective (pp. 121-160). Cambridge, England: Cambridge University Press.

Hine, C. (2008). Virtual ethnography: Modes, varieties, affordances. The SAGE Handbook of Online Research Methods, 257-270.

Hirsch, T. (2017). An ethnographic study of transnational family language policy in Facebook communities across time [Doctoral dissertation, University of California, Santa Barbara].

Hirsch, T., \& Lee, J. S. (2018). Understanding the complexities of transnational family language policy. Journal of Multilingual and Multicultural Development, 39(10), 882-894.

Hochschild, A., \& Machung, A. (1989). The second shift: Working parents and the revolution at home. London, England: Penguin.

Hoffman, D. L. (2014). Investigating phenomenological translanguaging among deaf adult bilinguals engaging in reading tasks. Beaumont, TX: Lamar University.

Holliday, A. (2006). Native-speakerism. ELT Journal, 60, 385-387. doi:10.1093/ elt/cc1030 
Holliday, A. (2013). 'Native speaker' teachers and cultural belief. In S. Houghton \& D. J. Rivers (Eds.), Native-Speakerism in Japan: Intergroup Dynamics in Foreign Language Education (pp. 17-27). Bristol: Multilingual Matters.

Holliday, A. (2015). Native-Speakerism: Taking the concept forward and achieving cultural belief. In A. Swan, P. Aboshiha, \& A. Holliday (Eds.), (En)Countering Native- Speakerism (pp. 11-25). New York, NY: Palgrave Macmillan. Retrieved from http:/link.springer.com/ chapter/10.1057/9781137463500 2

Inbar-Lourie, O. (2005). Mind the gap: Self and perceived native speaker identities of EFL teachers. In L. van Lier (Ed.), Non-Native Language Teachers (pp. 265-281). New York, NY: Springer US. Retrieved from http://link.springer.com/ chapter/10.1007/0-387-24565-0 14

Kayam, O., \& Hirsch, T. (2014). Socialization of language through family language policy: A case study. Psychology of Language and Communication, 18(1), 53-66.

King, K. A., \& Fogle, L. W. (2016). Family language policy. Language Policy and Political Issues in Education, 1-13.

Kirsch, C. (2012). Ideologies, struggles and contradictions: An account of mothers raising their children bilingually in Luxembourgish and English in Great Britain. International Journal of Bilingual Education and Bilingualism, 15(1), 95-112.

Kanayama, T. (2003). Ethnographic research on the experience of Japanese elderly people online. New Media \& Society, 5(2), 267-288.

Kozinets, R. V. (1998). On netnography: Initial reflections on consumer research investigations of cyberculture. ACR North American Advances.

Kużelewska, E. (2016). Language policy in Switzerland. Studies in Logic, Grammar and Rhetoric, 45(1), 125-140.

Lanza, E., \& Wei, L. (2016). Multilingual encounters in transcultural families. Journal of Multilingual and Multicultural Development, 37(7), 653-654.

Lave, J., \& Wenger, E. (1991). Situated learning: Legitimate peripheral participation. Cambridge, England: Cambridge University Press.

Lysloff, R. T. A. (2003). Musical community on the Internet: An onlineethnography. Cultural Anthropology, 18(2), 233-63.

Madge, C. and O'Connor, H. (2006). Parenting Gone Wired: Empowerment of New Mothers on the Internet? Social \& Cultural Geography, 7(2) April: 199-220.

Mackey, W. F. (1970). A typology of bilingual education. Foreign Language Annals, 3(4),596-606.

Markham, A. (1998). Life online: Researching real experience in virtual space. AltaMira Press.

Okita, T. (2002). Invisible work: Bilingualism, language choice and childrearing in intermarried families (Vol. 12). John Benjamins Publishing. 
Patton. M. (1980). Qualitative evaluation methods. Beverly Hills, California: SAGE.

Pavlenko, A. (2001). Bilingualism, gender, and ideology. International Journal of Bilingualism, 5(2), 117-151.

Pavlenko, A. (2002). Poststructuralist approaches to the study of social factors in language learning and use. In V. Cook (Ed.), Portraits of the L2 User (pp. 277-302). Clevedon, UK: Multilingual Matters.

Perna, L. W. (2003). The status of women and minorities among community college faculty. Research in Higher Education,44(2), 205-240.

Piller, I. (1999). "Something tattooed on my forehead": Gendered performances and perceptions of linguistic and national identity. In Wahrnehmung und Herstellung von Geschlecht (pp. 117-126). VS Verlag für Sozialwissenschaften.

Piller, I. (2002). Bilingual couples talk. Amsterdam, The Netherlands: John Benjamins.

Piller, I., \& Gerber, L. (2018). Family language policy between the bilingual advantage and the monolingual mindset. International Journal of Bilingual Education and Bilingualism, 1-14.

Piller, I. \& Pavlenko, A. (2004). Bilingualism and gender. In T. Bhatia \& W. Ritchie (Eds.), Handbook of Bilingualism (pp. 489-511). Oxford, UK: Blackwell.

Spitzmüller, C., \& Matthews, R. A. (Eds.). (2016). Research perspectives on work and the transition to motherhood. New York: Springer.

Spolsky, B. (2001). Language in Israel: Policy, practice and ideology. Georgetown University Round Table on Languages and Linguistics, $1999,164$.

Spolsky, B. (2012). Family language policy - The critical domain. Journal of Multilingual and Multicultural Development, 33(1), 3-11.

Turkle, S. (1995). Life on the Screen: Identity in the Life of the Internet. Simon \& Shuster, New York, 196.

Uhlenberg, P., \& Cooney, T. M. (1990). Male and female physicians: Family and career comparisons. Social Science \& Medicine, 30(3), 373-378.

Valdés, G., González, S. V., García, D. L., \& Márquez, P. (2003). Language ideology: The case of Spanish in departments of foreign languages. Anthropology \& Education Quarterly, 34(1), 3-26.

van Dijk, T. A. (1998). Ideology: A multidisciplinary approach. Thousand Oaks, CA: SAGE.

Walters, K. (1996). Gender, identity, and the political economy of language: Anglophone wives in Tunisia. Language in Society, 25(4), 515-555. doi:10.1017/S0047404500020807

Wang, W. (2012). The rise of intermarriage. Washington, DC: Pew Research Center. 
Ward, K., \& Wolf-Wendel, L. (2004). Academic motherhood: Managing complex roles in research universities. The Review of Higher Education, $27(2), 233-257$.

Wei, L. (2012). Language policy and practice in multilingual, transnational families and beyond. Journal of Multilingual and Multicultural Development, 33(1), 1-2.

Weinreich, U. (1968). Languages in contact. The Hague: Mouton.

Wenger, E. (1998). Communities of practice: Learning as a social system. Systems Thinker, 9(5), 2-3.

Whitty, M. T. (2003). Cyber-flirting: Playing at love on the Internet. Theory \& Psychology, 13(3), 339-357.

Williams, C. (1994). Arfarniad o ddulliau dysgu ac addysgu yng nghyd-destun addysg uwchradd ddwyieithog [An evaluation of teaching and learning methods in the context of bilingual secondary education] [Unpublished doctoral thesis, University of Wales, Bangor].

Zentella, A. C. (1987). Language and female identity in the Puerto Rican community. Women and Language in Transition, 167-179.

Zubrzycki, K. (2019). Am I perfect enough to be a true bilingual? Monolingual bias in the lay perception and self-perception of bi- and multilinguals. International Review of Applied Linguistics in Language Teaching, 57(4), 447-495.

AAPOR: American Association for Public Opinion Research (see: https://www. aapor.org/Standards-Ethics/Institutional-Review-Boards/IRB-FAQs-forSurvey-Researchers.aspx\#separate\%20consent)

AOiR: Association of Internet Researchers, (https://aoir.org/ethics/) 


\section{Annex}

\section{Academic Motherhood and Multilingualism}

We are interested in exploring how academic mothers SPECIFICALLY approach bilingualism/multilingualism in their lives and with their children (whether it be through translocation, marriage/partnership, or choice).

All of the responses here are anonymous, but please, if you are willing to take part in future studies, include your contact information at the end of the survey or e-mail me directly at tijana.hirsch@gmail.com with your information. Also, please forward the survey to any other academic mamas with two or more languages in their lives. Thank you so much!

Thank you from fellow academic mamas!

Dr. Tijana Hirsch (fellow academic mama on and off FB) and

Dr. Orly Kayam (mom \& academic)

Wingate Academic College

\section{Questions}

1. What is your academic status/appointment?

2. Do you have additional language(s) in your life through: (select all that apply)

Translocation/move

Marriage/partnershipChoice (learning/maintaining a language

learned previously)

Heritage

3. Do you live in the country you were born in?

Yes

No

4. Have you lived outside of the country you were born in?

Yes

No

5. If you do not live in the country that you were born in, prior to the move, did you think the move was permanent? (Please select the one that best fits your then-state of mind)

Yes

No 
6. If you lived in another country in the past, did you think that your move was going to be permanent or temporary PRIOR to the move? (Choose the best answer please)

Permanent

Temporary

7. If you live or have ever lived in a linguistically new setting please share what you remember regarding your language learning and new language navigation? Did you love it? Hate it? Do you have any specific memories of something someone said? Did?

8. Do you consider yourself to be monolingual/bilingual/multilingual? Monolingual

Bilingual

Multilingual

9. Which languages do you speak?

10. Is your partner (if relevant) monolingual/bilingual/multilingual Monolingual

Bilingual

Multilingual

11. Which languages does $\mathrm{s} / \mathrm{he} \mathrm{speak?}$

12. What do you do with the languages in your life, with your children? (Please share what you do, what they do, how you feel, how they feel, what you wish, plan, hope, and if you've changed something along the way)

13. Are there languages in your repertoire/heritage/past that you choose not to maintain/pass on/learn/teach to your children? (Why not? Please reflect below)

14. Which language(s) are you working on learning/maintaining?

15. Why is/are this/these language(s) important to you?

16. How does the "academic" part of yourself contribute to the above decisions/approaches, if at all?

17. Is your partner an academic?

Yes

No

18. What is his/her/their position on language learning/maintenance in your family?

19. What is the dominant language of the country you live in?

English

Other: 
20. Are your children bilingual/multilingual?

Yes

No

21. How do you define bilingualism/multilingualism?

22. Is there anything else you would like to add? 